\title{
Disappearances of Individuals From Social Groups Have Implications for Understanding Natal Dispersal in Monogamous Owl Monkeys (Aotus azarai)
}

\author{
EDUARDO FERNANDEZ-DUQUE ${ }^{1,2 *}$ AND CALEB HUNTINGTON ${ }^{3}$ \\ ${ }^{1}$ Center for Reproduction of Endangered Species, Zoological Society of San Diego, \\ San Diego, California \\ ${ }_{3}^{2}$ Centro de Ecología Aplicada del Litoral, Corrientes, Argentina \\ ${ }^{3}$ Actuarial Department, Massachusetts Workers Compensation Bureau, Massachusetts
}

The socially monogamous owl monkeys (Aotus spp.) live in small groups of two to five individuals. We used monthly demographic data collected from 16 social groups between 1997-2001 to estimate the age of disappearance from their natal groups and the timing of those disappearances in a population of owl monkeys (Aotus azarai azarai) in Formosa, Argentina. We applied survival analysis techniques to 48 months of observations of 47 individuals to construct age-specific probabilities of disappearance. Two-thirds of the individuals (eight of 12), for which disappearance could be well timed, disappeared at around 2 years of age. The average age at disappearance for these individuals was 29 months $( \pm 8)$, whereas the mean age of disappearance obtained from the survival analysis of censored and uncensored data was almost 3 years (mean $\pm \mathrm{SD}, 35 \pm 3$ months). Ninety-two percent of all disappearances of adult size individuals (11 of 12) occurred around the birth season. Our data suggest that at least some individuals disperse soon after sexual maturation while others remain for up to 4 years in their natal groups. Am. J. Primatol. 57:219-225, 2002. (C) 2002 Wiley-Liss, Inc.

Key words: Aotus; dispersal; owl monkeys; monogamy; survival analysis

\section{INTRODUCTION}

The owl monkeys (Aotus spp.) of Central and South America are one of the few socially monogamous primates in the world. Owl monkeys live in small groups of two to five individuals [Wright, 1985; Aquino \& Encarnacion, 1994; Fernandez-Duque et al., 2001]. These social groups usually include a maximum of three adult-size individuals [Fernandez-Duque et al., 2001] indicating that natal dispersal might occur when individuals are 2 or 3 years of age and they have

Contract grant sponsor: L.S.B. Leakey Foundation; Contract grant sponsor: Center for Reproduction of Endangered Species, Zoological Society of San Diego; Contract grant sponsor: Douroucouli Foundation; Contract grant sponsor: Argentinean National Council for Scientific and Technological Research; Contract grant number: PIP 0051/98, CONICET.

*Correspondence to: Eduardo Fernandez-Duque, Center for Reproduction of Endangered Species, San Diego Zoo, PO Box 120551, San Diego, CA 92112-0551. E-mail: efduque@sandiegozoo.org

Received 5 November 2001; revision accepted 28 May 2002

DOI 10.1002/ajp.10045

Published online in Wiley InterScience (www.interscience.wiley.com). 


\section{0 / Fernandez-Duque and Huntington}

reached adult size. Still, there have never been any published data to evaluate age at dispersal in Aotus spp. We estimated the age at disappearance from their social groups for 12 adult-size individuals of known date of birth. We also conducted a survival analysis to estimate age-specific probabilities of disappearance using 4 years of monthly data on group size and composition collected from 16 social groups of owl monkeys (Aotus azarai azarai). Finally, we examined the potential influence of group size on the probability of disappearance and the annual distribution of the disappearance events.

\section{METHODS}

\section{Data Collection}

We collected demographic data from a population of owl monkeys (A. a. azarai) in Formosa, Argentina (58 $\left.13^{\prime} \mathrm{W}, 25^{\circ} 54^{\prime} \mathrm{S}\right)$ between June 1997 and June 2001. We have presented information elsewhere on the structure of the population and the methodology used to collect demographic data [FernandezDuque et al., 2001; Fernandez-Duque et al., 2002]. During most of the data collection period, we were not able to sex or identify most of the animals. We recorded the birth dates of individuals born during the study to the nearest month [Fernandez-Duque et al., 2002]. We classified the infants and juveniles that were present at the beginning of the study as born in 1996 or 1995 based on their relative size. We were able to estimate a relatively narrow age range for these individuals since all births in the population occur between October and January [Fernandez-Duque et al., 2002].

We used information on changes in group size and composition to estimate age at disappearance, as well as the annual distribution of disappearance events. Owl monkeys are unequivocally of smaller size until they are 18 months old [Fernandez-Duque et al., 2001]. For the analyses, we attributed the disappearance of infants and juveniles of smaller size to death, since we have never observed solitary owl monkeys of infant or juvenile size.

We estimated age-specific probabilities of dispersal using nonparametric survival analysis for right-censored, left-truncated data. In survival analysis, "right-censored" data refers to a data set in which some individuals have not yet experienced the event of interest at the end of the observation period. In the present context, a "right-censored" observation indicates that the individual had not disappeared by the end of the study period (e.g., observation 47, Table I). "Left-truncated" data refers to data in which some individuals were unavailable for observation of the event of interest at early ages. In this context, a lefttruncated observation is that of an individual born before the study began (e.g., observation 29, Table I). We constructed a survival function for right-censored, left-truncated observations using standard statistical techniques. We analyzed 48 months of observations of 47 individuals in 16 social groups (Table I).

Many individuals born in 1999 and 2000 were still in their groups as of June 2001, the month for which the most recent data are available. We treated these individuals as disappearing in an open interval after June of 2001 (right-censored observations, $n=29$ ). At the start of the study, nine juveniles or infants were present from the 1995 or 1996 birth seasons. These observations are lefttruncated because any disappearances or mortality that might have taken place prior to June 1997 would not have been observed.

We analyzed the annual distribution of disappearance events assigning observations to 2-month periods. We treated each disappearance as occurring at the midpoint of the period between the last time the individual was seen 
Owl Monkey Dispersal / 221

TABLE I. Estimated Age Range at Disappearance

\begin{tabular}{|c|c|c|c|c|c|}
\hline $\begin{array}{c}\text { Individual } \\
\text { no. }\end{array}$ & Group & $\begin{array}{l}\text { Date of } \\
\text { birth }\end{array}$ & $\begin{array}{c}\text { Last month } \\
\text { seen }\end{array}$ & $\begin{array}{l}\text { First month } \\
\text { missing }^{\mathrm{a}}\end{array}$ & $\begin{array}{l}\text { Age range at } \\
\text { disappearance }\end{array}$ \\
\hline 1 & $\mathrm{CC}$ & Nov-97 & Nov-97 & Jan-98 & $0-3$ \\
\hline 2 & Colman & Dec-00 & Jun-01 & $*$ & $>6$ \\
\hline 3 & Sur de G & Dec-00 & Jun-01 & $*$ & $>6$ \\
\hline 4 & Corredor & Dec-00 & Jun-01 & $*$ & $>6$ \\
\hline 5 & F1200 & Oct-99 & Apr-00 & May-00 & $6-7$ \\
\hline 6 & $\mathrm{C} 0$ & Nov-00 & Jun-01 & * & $>7$ \\
\hline 7 & E500 & Nov-00 & Jun-01 & $*$ & $>7$ \\
\hline 8 & F1200 & Nov-00 & Jun-01 & $*$ & $>7$ \\
\hline 9 & A900 & Nov-00 & Jun-01 & $*$ & $>7$ \\
\hline 10 & B68 & Oct-00 & Jun-01 & $*$ & $>7$ \\
\hline 11 & $\mathrm{CC}$ & Oct-00 & Jun-01 & $*$ & $>8$ \\
\hline 12 & D1200 & Oct-00 & Jun-01 & $*$ & $>8$ \\
\hline 13 & CAMP & Oct-00 & Jun-01 & $*$ & $>8$ \\
\hline 14 & F1200 & Jan-99 & Dec-99 & Dec-99 & $11-13$ \\
\hline 15 & CAMP & Jan-99 & Nov-99 & Jan-00 & $10-15$ \\
\hline 16 & D500 & Jan-98 & Feb-99 & Feb-99 & $13-15$ \\
\hline 17 & Colman & Dec-99 & Jun-01 & $*$ & $>18$ \\
\hline 18 & $\mathrm{CC}$ & Nov-99 & Jun-01 & $*$ & $>19$ \\
\hline 19 & E500 & Nov-99 & Jun-01 & $*$ & $>19$ \\
\hline 20 & D800 & Nov-99 & Jun-01 & $*$ & $>19$ \\
\hline 21 & A900 & Nov-99 & Jun-01 & $*$ & $>19$ \\
\hline 22 & D500 & Oct-99 & Jun-01 & $*$ & $>20$ \\
\hline 23 & $\mathrm{CO}$ & Oct-99 & Jun-01 & $*$ & $>20$ \\
\hline 24 & D100 & Oct-99 & Jun-01 & $*$ & $>20$ \\
\hline 25 & D1200 & Oct-99 & Jun-01 & $*$ & $>20$ \\
\hline 26 & CAMP & Oct-99 & Jun-01 & $*$ & $>20$ \\
\hline 27 & Corredor & Oct-99 & Jun-01 & $*$ & $>20$ \\
\hline 28 & $\mathrm{CC}$ & Oct-98 & Jul-00 & Aug-00 & $21-22$ \\
\hline 29 & INTRUSO & Jan-97 & Oct-98 & Oct-98 & $21-24$ \\
\hline 30 & D800 & Jan-99 & Oct-00 & Oct-00 & $21-24$ \\
\hline 31 & D1200 & Jan-96b & Oct-97 & Dec-97 & $21-26$ \\
\hline 32 & F1200 & Nov-97 & Oct-99 & Nov-99 & $23-25$ \\
\hline 34 & $\mathrm{C} 0$ & Jan-97 & Dec-98 & Dec-98 & $23-26$ \\
\hline 35 & $\mathrm{C} 0$ & Jan-96 & Feb-98 & Feb-98 & $25-28$ \\
\hline 36 & $\mathrm{CO}$ & Jan-96 & Feb-98 & Feb-98 & $25-28$ \\
\hline 37 & B68 & Jan-99 & Jun-01 & $*$ & $>29$ \\
\hline 38 & E500 & Nov-98 & Jun-01 & $*$ & $>31$ \\
\hline 39 & D500 & Oct-98 & Jun-01 & $*$ & $>32$ \\
\hline 40 & D1200 & Oct-98 & Jun-01 & $*$ & $>32$ \\
\hline 41 & $\mathrm{CC}$ & Jan-97 & Sep-99 & Oct-99 & $32-36$ \\
\hline 42 & $\mathrm{C} 0$ & Dec-97 & Nov-00 & Nov-00 & 35 \\
\hline 43 & E500 & Jan-98 & Jun-01 & $*$ & $>41$ \\
\hline 44 & INTRUSO & Jan-98 & Jun-01 & $*$ & $>41$ \\
\hline 45 & $\mathrm{C} 0$ & Jan-97 ${ }^{\mathrm{b}}$ & Aug-00 & Aug-00 & $43-46$ \\
\hline 46 & D100 & Jan-97 & Aug-00 & Sep-00 & $43-47$ \\
\hline 47 & B68 & Jan-97 ${ }^{\mathrm{b}}$ & Jun-01 & $*$ & $>53$ \\
\hline
\end{tabular}

${ }^{a}$ Asterisk indicates individuals still present at the end of the study.

${ }^{\mathrm{b}}$ Estimated DOB.

in the group and the first time it was noted as missing. We report the timing of 12 disappearances that were possible dispersals, and that we were able to time to the nearest month. 


\section{RESULTS}

For 17 of the 47 individuals we were able to estimate a relatively narrow agerange of disappearance (Table I). Five of these animals disappeared from their groups when they were still of infant or juvenile size, and were considered dead. Three of them disappeared when they were approximately 1 year old (range: 10 15 months), whereas the other two disappeared soon after being born and at 6 months of age, respectively.

There were 12 individuals of adult size that disappeared during the study. The average age at disappearance for these individuals was approximately $2 \frac{1}{2}$ years $(\mathrm{n}=12$, mean $\pm \mathrm{SD}, 29 \pm 8$ months). Two-thirds of these individuals disappeared around 2 years of age $(n=8)$, whereas the remaining ones stayed in their natal groups until they were $3(n=2)$ or $4(n=2)$ years old.

Thirty individuals were still living in their natal group at the end of the study. Of these, seven were older than 2 years of age. When we incorporated censored data (all 47 observations) in the survival analysis, the mean age of disappearance was slightly higher (mean $\pm \mathrm{SD}, 35 \pm 3$ months).

The probability of disappearance might be related to the size of each particular group, not to a population-specific group size. Certain "small" groups in the population have never included more than four individuals, whereas "large" groups have been observed with five, six, or seven individuals [Fernandez-Duque et al., 2001]. Disappearances recorded from small groups $(\mathrm{n}=4$ events, 4 groups) only occurred when the groups had reached their historical maximum size of four individuals [see Table II in Fernandez-Duque et al., 2001]. Disappearances recorded from "large" groups ( $\mathrm{n}=8$ events, 3 groups) also occurred when the groups were approaching their historical maximum size, but the group size in these cases was five ( $\mathrm{n}=6$ events) or seven $(\mathrm{n}=2$ events). In other words, disappearances may be related to the group reaching its own maximum size, not a population-specific one.

Most disappearances (92\%, 11 of 12) occurred during the birth season (October-November, $\mathrm{n}=5$ ), right before it (August-September, $\mathrm{n}=3$ ), or soon after it (December-January, $\mathrm{n}=3$ ). The remaining individual disappeared between February and March $(\mathrm{n}=1)$.

\section{DISCUSSION}

Our data are preliminary and should be interpreted with caution. The most robust inferences can be made relative to the disappearance of individuals of small size. Given the current knowledge on primate dispersal and owl monkey life history, it seems unlikely that these nonreproductive animals dispersed. We concluded that the infants and juveniles that disappeared had died, since we have never observed a non-adult individual ranging solitarily.

The results also suggest that more than half of the adult-size individuals that disappeared did so when they were between $2 \frac{1}{2}$ and 3 years of age. First, we will argue that an important number of those disappearances could be attributed to dispersal occurring soon after sexual maturation, and then discuss other possible explanations for those disappearances. In captivity, owl monkeys (A. lemurinus) reach maturity at approximately 2 years of age, as indicated by measures of body weight, growth of the subcaudal scent gland, and circulating reproductive hormones [Dixson et al., 1980; Dixson, 1983, 1994]. Although we have not yet systematically evaluated the timing of sexual maturation in $A$. azarai, eight individuals that were captured when they were between 22 and 28 months of age showed some evident signs of sexual maturation (e.g., adult-like development of 
nipples or scent glands (unpublished data)). Two- or 3-year-old individuals sometimes lag behind the rest of the group or sleep in different trees, suggesting that some peripheralization may start taking place around that time (personal observation). The most robust evidence that at least some animals disperse at this age comes from one radio-collared 3-year-old female who was found dead $600 \mathrm{~m}$ away from her territory, and a 3-year old male who has been ranging solitarily for the last 9 months. Dispersal around the time of sexual maturation has also been reported in other monogamous primates [Chivers and Raemaekers, 1980; Tilson, 1981; Muller and Schildger, 1994; Palombit, 1994; Brockelman et al., 1998].

There are other potential explanations for those disappearances that deserve consideration. It is possible that given our inability to distinguish among adultsize individuals, the animal that we recorded as "disappeared" was in fact not the 2- or 3-year-old individual, but one of the reproducing adults. Although this is a possibility, there are significant behavioral differences between adults and subadults that would have caught our attention. For example, the disappearance of the adult male would have been noticed since there is a very close association between the young and the adult males [Wright, 1984; Rotundo et al., in press]. The disappearance of an adult female could easily have been noticed during lactation. After lactation, it would have been harder to differentiate behaviorally adult females from subadult ones because the young rarely associate with the adult females (personal observation). A second alternative is that following the dispersal or death of an individual, an owl monkey ranging solitarily, or one from a neighboring group, rather quickly replaces the disappeared individual. Should this happen, group size would remain unchanged despite a most significant change in group composition. These kinds of replacements have been documented in gibbons [Palombit, 1994], and there is no reason to believe they could not happen in owl monkeys as well.

Our analyses indicate that there are also some individuals that may stay in their natal groups for up to 4 years. It is then possible that owl monkeys are delaying dispersal for significant periods of time after they have reached sexual maturation. Data from two radio-collared individuals of known date of birth that were still in their natal groups at 42 and 39 months of age, respectively, give further support for the existence of delayed dispersal in the population (unpublished data). Delayed dispersal has been reported in the socially monogamous gibbon. An 18-year study of Lar gibbons (Hylobates lar) in Thailand found that five males dispersed on average 2 years after reaching sexual maturity [Brockelman et al., 1998].

The lack of unoccupied suitable areas of the forest where dispersing animals could establish their own territory may lead offspring to postpone dispersal. All of the potential dispersal events occurred between August-March, with more than $90 \%$ occurring around the time of the birth season. The concentration of these events around the birth season raises the possibility that births within the group may trigger the process of dispersal. On the other hand, it is also possible that the timing of dispersal is set to take place in anticipation of the May-June mating season. We have not yet been able to characterize whether the peripheralization of subadults that precedes dispersal is triggered by aggression from within the group or if it is intrinsic to the dispersing individual. In captive studies there was no increase in parent aggression toward offspring as the latter reached sexual maturity (Dixson, personal communication).

The fate of the disappeared individuals remains largely unknown. The existence of a nonterritorial floater population deserves consideration despite our previous dismissal of this possibility. In the past we considered the existence of an 
important number of floaters in the population to be unlikely, given the low frequency of encounters with solitary animals [Fernandez-Duque et al., 2002]. Still, recent evidence from radio-collared animals and playback experiments suggests otherwise. A 3-year-old radio-collared male has been ranging solitarily for 9 months (September 2001-May 2002). During this period, we have only encountered this animal while using the telemetry equipment, suggesting that without a radio-collar it would have been unnoticed. Further evidence for the existence of a number of unnoticed floaters comes from a set of recently conducted preliminary playback experiments. When loud vocalizations were played to eight different groups, two, three, and even four solitary animals appeared in the area where the playback was being conducted (Ramirez-Llorens, personal communication).

Our data on disappearances of adult-size individuals from social groups of owl monkeys lends support to a complex process of natal and secondary dispersal. The evidence points to some individuals leaving their natal groups around the time of sexual maturation, whereas others show facultative delayed dispersal. Still, it is also possible that some individuals are finding reproductive opportunities within their natal territory, as has been described for gibbons [Palombit, 1994]. Gibbons have been reported to secure a territory and a mate with various strategies, including forcible replacement of a resident adult [Brockelman et al., 1998], establishment of a new territory [Tilson, 1981], and joining of a widowed or divorced individual [Palombit, 1994]. The relative importance of each of these strategies in owl monkeys will require data from identified and sexed individuals of known date and place of birth. It is hoped that the ongoing studies of collared owl monkeys will shed light on our limited understanding of dispersal in monogamous primates.

\section{ACKNOWLEDGMENTS}

This research was supported by grants to E.F.D. from the L.S.B. Leakey Foundation; the Center for Reproduction of Endangered Species, Zoological Society of San Diego; the Douroucouli Foundation; and the Argentinean National Council for Scientific and Technological Research (PIP 0051/98, CONICET). The authors thank the numerous Earthwatch and UREP volunteers, and the Argentinean and foreign students who helped at different stages of the project. Special thanks to Mr. E. Arauz and Mr. J. Adams at Estancia Guaycolec for their continuous support. The authors thank M. Andrews, A.F. Dixson, D. Mayeaux, C.R. Valeggia, and two anonymous reviewers for their useful comments on the manuscript.

\section{REFERENCES}

Aquino R, Encarnacion F. 1994. Owl monkey populations in Latin America: field work and conservation. Aotus: the owl monkey. Baer JF, Weller RE, Kakoma I, editors. San Diego: Academic Press. p 59-95.

Brockelman WY, Reichard U, Treesucon U, Raemaekers JJ. 1998. Dispersal, pair formation and social structure in gibbons (Hylobates lar). Behav Ecol Sociobiol 42:329-339.

Chivers DJ, Raemaekers JJ. 1980. Long-term changes in behavior. Malayan Forest pri- mates. Ten years' study in tropical rain forest. Chivers DJ, editor. New York: Plenum Press. p 209-260.

Dixson AF, Gardner JS, Bonney RC. 1980. Puberty in the male owl monkey (Aotus trivirgatus griseimembra): a study of physical and hormonal development. Aotus, adolescence, testosterone, scent glands, secretions, hormones, reproduction, body weight, testes. $2844 \mathrm{p}$.

Dixson AF. 1983. The owl monkey (Aotus trivirgatus). Reproduction in New World 
primates. New models in medical sciences. Hearn JP, editor. Lancaster: International Medical Publishers. p 69-113.

Dixson AF. 1994. Reproductive biology of the owl monkey. Aotus: the owl monkey. Baer JF, Weller RE, Kakoma I, editors. San Diego: Academic Press. p 113-132.

Fernandez-Duque E, Rotundo M, Sloan C. 2001. Density and population structure of owl monkeys (Aotus azarai) in the Argentinean Chaco. Am J Primatol 53:99-108.

Fernandez-Duque E, Rotundo M, RamirezLlorens P. 2002. Environmental determinants of birth seasonality in owl monkeys (Aotus azarai) of the Argentinean Chaco. Int J Primatol 23:639-656.

Muller K-H, Schildger J. 1994. Capture and radio-telemetry of masked titi monkeys, Callicebus personatus melanochir. Neotrop Primates 2:7-8.
Palombit R. 1994. Dynamic pair bonds in hylobatids: implications regarding monogamous social systems. Behaviour 128: 65-101.

Rotundo M, Fernandez-Duque E, Giménez M. Cuidado biparental en el mono de noche (Aotus azarai azarai) de Formosa, Argentina. Neotrop Primates (in press).

Tilson RL. 1981. Family formation strategies of Kloss's gibbons. Folia Primatol 35:259 287.

Wright PC. 1984. Biparental care in Aotus trivirgatus and Callicebus moloch. Female primates: studies by women primatologists. Small M, editor. New York: Alan R. Liss, Inc. p 59-75.

Wright PC. 1985. The costs and benefits of nocturnality for Aotus trivirgatus (the night monkey). Dissertation. City University of New York. 